\title{
Interpretação constitucional comparativa: aproximação crítica e arcabouço metodológico
}

\author{
Alonso Freire \\ Professor Assistente da Universidade Federal do Maranhão. Professor da UNICEUMA e do \\ UNIEURO. Assessor de Ministro do Supremo Tribunal Federal. Doutorando em Direito \\ Público pela Universidade do Estado do Rio de Janeiro. Mestre em Direito Constitucional \\ pela Universidade Federal de Minas Gerais.
}

\section{Resumo}

Este artigo trata da interpretação constitucional comparativa, especialmente em casos envolvendo direitos fundamentais. Inicialmente, é feita uma exposição do debate sobre a invocação judicial de fontes jurídicas estrangeiras. Em seguida, são explicados os três tipos de invocação dessas fontes: obrigatória, recomendável e voluntária. O propósito do artigo é oferecer justificativas normativas para a prática da invocação voluntária. Para isso, busca-se repropor, em formas mais atenuadas, dois principais argumentos já oferecidos por Jeremy Waldron. Após serem expostas as falhas desses argumentos, extraem-se duas conclusões. Primeiro, juízes e tribunais de um país podem se beneficiar não apenas de um consenso jurídico entre nações, mas também de experiências únicas de outros países. Para isso, são necessários critérios de comparabilidade. Segundo, a melhor recomendação não é a de se tratar casos iguais de forma igual no mundo, mas a de se tratar casos comparáveis de forma comparativa. Ao final, propõe-se um arcabouço metodológico para a análise de comparabilidade na interpretação judicial dos direitos fundamentais.

\section{Palavras-chave}

Interpretação; Direito Comparado; Direitos Fundamentais; Comparabilidade.

\section{Comparative constitutional interpretation: critical approach and methodological framework}




\begin{abstract}
This paper addresses the comparative constitutional interpretation problem, especially in fundamental rights cases. Firstly, it exposes of the debate on judicial use of foreign law. Then, it explains three kinds of use of foreign law: mandatory, advisable and voluntary uses. The purpose of the paper is to offer a normative justification for voluntary use. For this, it proposes two main arguments already offered by Jeremy Waldron, but in weaker forms. After the failures of these arguments being exposed, two main conclusions are drawn. First, the courts and judges of a country can benefit themselves not only of a legal consensus among nations but also of unique experiences from other countries. For this, comparability criteria are necessary. Second, the best advice is not to treat like cases alike in the world, but to treat comparable cases in a comparative way. Finally, it proposes a methodological framework for the comparability analysis in the judicial interpretation of constitutional rights.
\end{abstract}

Keywords

Interpretation; Comparative Law; Fundamental Rights; Comparability.

\title{
Sumário
}

Introdução; 1. A resistência à comparação judicial voluntária; 2. Propósitos da comparação no Direito Constitucional e a ideologia no Direito Comparado; 3. A ideia de "Leis Parcialmente Comuns a toda Espécie Humana" e seus desdobramentos; 3.1 Recorrer a um consenso jurídico entre nações?; 3.2. Tratar casos iguais de forma igual ao redor do mundo?; 4. Um arcabouço para a análise de comparabilidade na interpretação judicial comparativa dos direitos fundamentais; 4.1. Selecionando o(s) paíse(s); 4.2. Verificando as características da(s) sociedade(s); 4.3. Atentando para os aspectos situacionais; 5. Tratando casos comparáveis comparativamente; Conclusão; Referências bibliográficas.

\section{Introdução}

O uso do direito estrangeiro e do direito internacional na interpretação constitucional por tribunais nacionais em suas decisões é hoje uma prática cada vez mais comum ao redor do mundo. Ela tem sido observada em vários países, como, por exemplo, África do Sul, Alemanha, Argentina, Austrália, Brasil, Canadá, Espanha, Estados Unidos, França, Holanda, Hungria, Índia, Inglaterra, Israel, Itália, Rússia, dentre tantos outros (FREIRE, 2014; GROPPI, 2013). Tem-se observado igualmente que cortes internacionais e nacionais também têm se engajado em uma análise comparativa com o propósito de saber como outras cortes nacionais têm interpretado as normas de Direito Internacional, prática que tem motivado alguns estudiosos a questionarem o surgimento de um "Direito Internacional Comparado" (ROBERTS, 2011). Portanto, com cada vez mais frequência, 
cortes tanto nacionais como internacionais têm realizado comparações judiciais ao decidirem casos submetidos às suas respectivas jurisdições.

De um modo geral, esse fenômeno tem dado origem a uma batalha de metáforas, já sendo possível encontrar na literatura estrangeira diversas denominações ${ }^{1}$. Conquanto a literatura a respeito já exista em quantidade surpreendente, o que se nota é uma predominância de estudos descritivos de uma prática já inegável. Embora a invocação dos direitos estrangeiro e internacional por muitos tribunais constitucionais e, no Brasil, pelo Supremo Tribunal Federal, seja fato já constatado, o que permanece em aberto, aqui e alhures, é a questão sobre se essas fontes devem ou não devem ser invocadas e quais critérios devem ser empregados por eles ao recorrem a elas. Em resumo, não se tem dado uma justificativa para essa prática, ou seja, não se tem oferecido uma resposta à pergunta a propósito da necessidade ou não dela, pelo menos não como se deveria.

A justificativa é devida, sobretudo, a um tipo específico de invocação de fontes estrangeiras e internacionais. Há três tipos (BOBEK, p. 19-35). O primeiro deles pode ser chamando de "obrigatório". Ele é assim chamado quando a ordem constitucional doméstica obriga os tribunais nacionais a usarem o direito internacional ou estrangeiro no momento em que eles decidem alguns tipos de casos ou todos os tipos de casos que lhes competem julgar. O segundo tipo é chamado de uso "aconselhável". Aqui, não há nenhuma obrigação de o tribunal recorrer a fontes não domésticas, mas há certo consenso, recomendação ou indicação para a consulta de fontes externas como sendo o correto modo de um juiz ou tribunal proceder. A recomendação, que geralmente é doutrinária, pode, por exemplo, se apoiar no fato de que muitos países transplantam leis ou normas constitucionais de outros ou mesmo se inspiram em determinadas leis ou constituições estrangeiras e normas internacionais ao elaborarem suas próprias normas. Diferentemente do uso obrigatório, nessa categoria, o material jurídico externo a ser utilizado não é mais uma fonte diretamente recomendada pelo direito interno, mas apenas uma fonte persuasiva de inspiração no processo de interpretação. O terceiro e último tipo é o "voluntário". Ele ocorre quando, mesmo não havendo no sistema jurídico interno qualquer norma obrigando ou recomendado a consulta a fontes estrangeiras ou internacionais, os tribunais, ainda assim, recorrem a elas, mesmo àquelas nas quais não houve qualquer inspiração por parte do legislativo ou constituinte nacional. Embora as invocações voluntárias tanto de fontes estrangeiras como de fontes internacionais sejam

1Por exemplo, "migração de ideias constitucionais", "empréstimos constitucionais", "transplantes constitucionais", "comércio entre juízes", "fertilização constitucional cruzada" e "troca de ideias legais". 
questionáveis, neste artigo ocupar-me-ei apenas com a invocação voluntária de fontes estrangeiras, já que, a depender da origem das fontes invocadas (se estrangeiras ou internacionais), a discussão exige atenção a questões distintas, e não há espaço aqui para tratar todas elas.

Esclarecidas essas questões, devo agora expor meus propósitos neste artigo. Disse anteriormente que há poucos escritos acadêmicos voltados a oferecer uma justificativa normativa para a invocação judicial voluntária do direito estrangeiro. Há, de fato, poucos, mas, entre eles, há um particularmente bom. Em uma obra notável, Jeremy Waldron (2012) defende essa prática na interpretação dos direitos fundamentais, com base em dois argumentos poderosos. O primeiro deles é uma versão mais elaborada daquele que é o argumento mais utilizado pelos entusiastas da invocação judicial voluntária do direito estrangeiro: a possibilidade de se aprender com outras jurisdições. O segundo, por sua vez, é a aplicação em nível transnacional de uma reconhecida máxima: o dever de tratar casos iguais de forma igual. Neste artigo, reproponho esses argumentos em versões menos ambiciosas, de modo a oferecer justificativas menos exigentes e, a meu ver, mais promissoras para demonstrar que a comparação judicial de fontes estrangeiras é prática não apenas recomendável, mas, em certos casos, consiste em um dever dos órgãos judiciais ${ }^{2}$.

Embora o recurso judicial a fontes não domésticas já seja uma prática corriqueira e já observada em um número bastante significativo de países e cortes, há aqueles que se opõem a ela com argumentos dignos de consideração. Portanto, o artigo é organizado da seguinte forma. A primeira seção é dedicada aos argumentos contrários ao uso judicial voluntário de fontes estrangeiras. A segunda, por sua vez, busca demonstrar que a questão a propósito da propriedade ou possibilidade da comparação judicial constitucional está entrelaçada à discussão sobre os propósitos do próprio Direito Constitucional Comparado e a uma questão subjacente a ela: a ideologia no direito comparado. A seção seguinte expõe a ideia romana de "leis parcialmente comuns a toda espécie humana" resgatada por Waldron. Expõe também seus desdobramentos em dois argumentos normativos (um pragmático e um de princípio) em defesa da invocação judicial voluntária do direito estrangeiro em casos envolvendo direitos fundamentais. Após apontar o "excesso" de Waldron em relação ao seu primeiro argumento, elaboro, na quarta seção, um arcabouço para a análise de comparabilidade na interpretação judicial

${ }^{2}$ Mas uma delimitação é feita aqui. Muito embora a prática descrita envolva vários tipos de normas constitucionais, de fato, "[o] fenômeno é particularmente evidente no que tange à jurisprudência dos direitos fundamentais" (HIRSCHL, 2014, p. 236).

Revista Publicum

Rio de Janeiro, Número 2, 2016, p. 45-73.

http://www.e-publicacoes.uerj.br/index.php/publicum

DOI: $10.12957 /$ publicum.2016.23767 
comparativa dos direitos fundamentais. Na quinta, busco demonstrar que, mesmo na ausência do "consenso judicial" pensado por Waldron, há razões de princípio para realizar uma análise comparativa na interpretação judicial desses direitos. Proponho, ainda na última seção, uma forma atenuada de seu último argumento normativo. Ao final, uma avaliação sumária é feita a título de conclusão parcial.

\section{A resistência à comparação judicial voluntária}

Na discussão a propósito da possibilidade ou necessidade de comparação judicial, sobretudo, no uso voluntário de fontes não domésticas na jurisdição constitucional, o relativismo cultural (DONNELLY, 1984) se traduz em um particularismo, que enfatiza que as normas constitucionais, especialmente as definidoras de direitos fundamentais, devem ser interpretadas de acordo com as circunstâncias nacionais particulares e com a história constitucional nacional de cada país, bem como com a cultura jurídica e com a história da nação. "Em sua formulação mais forte", como o descreve um importante jurista, "o particularismo jurídico insiste que as constituições são aspectos importantes da identidade nacional" (CHOUDHRY, 1999, p. 830). Tendo em vista o grande valor dado às constituições nacionais, a interpretação das suas normas deve ser realizada a partir dos aspectos particulares de cada nação. Desse ponto de vista, para o particularismo, a jurisprudência comparativa não oferece qualquer ajuda, precisamente por que ela vem de fora de um determinado sistema jurídico. "Na melhor das hipóteses", diz Choudhry:

ela representa uma curiosidade estrangeira de interesse estritamente acadêmico e de pouca relevância prática. Na pior delas, seu uso é uma imposição ou mesmo uma forma de imperialismo jurídico (1999, p. 830).

Portanto, os particularistas levam muito a sério as diferenças existentes entre sistemas jurídicos. Para eles, embora exista um vocabulário familiar entre os mais distintos sistemas jurídicos (v.g. direitos, liberdades, deveres, poderes etc), isso significa apenas uma familiaridade superficial que pode encobrir profundas diferenças jurídicas não percebidas à primeira vista (ALFORD, 1986). Em síntese:

[o] argumento básico dos particularistas é o de que, em um mundo pósrealista, está fora de disputa que textos jurídicos são inerentemente 
ambíguos e que eles requerem fontes extratextuais para a interpretação $e$ aplicação deles em casos concretos (CHOUDHRY, 1999, p. 830).

Mas essas fontes não podem ser estrangeiras ou alheias àquelas reconhecidas pelo próprio sistema no qual o intérprete opera. Particularistas insistem, portanto, que os tribunais e juízes não devem olhar para experiências estrangeiras. Devem, pelo contrário, olhar para as fontes extralegais que conformam as normas de um sistema jurídico de uma nação em particular. Essas fontes seriam os costumes, as práticas sociais e jurídicas, a política, a tradição, a história etc.

Essa crença nas fontes extrajudiciais de cada comunidade política leva os particularistas a serem profundamente céticos quanto a viabilidade de empréstimos, transplantes e migrações de ideias constitucionais e a sustentarem uma postura de resistência a essas práticas, que é frequentemente associada a um tipo particular de nacionalismo jurídico. Como afirma Vicki Jackson:

Nessa visão, apenas aquelas normas jurídicas que foram adotadas de acordo com regras procedimentais controladas de uma comunidade jurídica nacional particular (e que, portanto, refletem a vontade e a identidade presumidas dessa comunidade particular) deveriam ser consideradas na interpretação do direito, e tanto o direito internacional como o direito estrangeiro são considerados com algum ceticismo ou suspeita como fontes de compreensão constitucional (2010, p. 8).

A resistência ao uso voluntário de fontes não domésticas pode decorrer não apenas de uma oposição baseada na cultural legal nacional, compreendida em um sentido mais amplo. Para os seus defensores, a ideia de constituição em si mesma pode ser vista como um convite à resistência ou indiferença ao direito estrangeiro e ao direito internacional em geral. $E$, segundo os particularistas, assim deve ser por que as constituições representam a auto-constituição e a auto-expressão de comunidades particulares. Vistas desta maneira, as constituições representam um papel "expressivista" (TUSHNET, 1999, p. 1225), revestindo a nação de identidade própria e auto-compreensão.

Com efeito: 
[s]e uma constituição é fundamentalmente um instrumento jurídico que olha para se próprio, cujo propósito é expressar os compromissos, limites e unicidade de um povo particular, as visões de cortes estrangeiras ou de tribunais internacionais são de pouco interesse ou podem até mesmo ser prejudiciais (JACKSON, 2010, p. 20).

Segundo essa lógica, não apenas as normas de direitos fundamentais, mas também todas as normas constitucionais devem receber das cortes nacionais interpretações próprias que estejam de acordo com o sistema jurídico, a história e, principalmente, com a cultura local. Por essa razão, insistem os particularistas, não é recomendável a consulta à experiência estrangeira na intepretação e aplicação de normas constitucionais de um modo geral ${ }^{3}$. Como alertou o juiz Antonin Scalia, da Suprema Corte norte-americana, um particularista de renome, "[n]ós não devemos esquecer que é uma Constituição para os Estados Unidos da América que estamos interpretando". ${ }^{4}$ Portanto, a resistência pode ter como fundamento a compreensão da constituição como um documento jurídico intimamente relacionado a uma sociedade e suas culturas.

Argumentos baseados na soberania popular e na democracia também são invocados em nome de uma postura de resistência. 0 risco, por exemplo, da subordinação do Direito Constitucional nacional a projetos particulares de outros sistemas com o possível comprometimento da soberania nacional é sempre citado como um ponto negativo. Na mesma esteira, a ideia de que a prática comparatista seria, de algum modo, antidemocrática também motiva uma postura de resistência. Parte-se do seguinte raciocínio: uma vez que a legitimidade de uma constituição decorre do fato de ela ter sido adotada democraticamente, sua interpretação deve ser realizada com base apenas naquilo que foi consentido. Por essa razão, buscar fundamentos em fontes estrangeiras ou internacionais voluntariamente representaria uma inconsistência com a ideia de autogoverno, e, na pior as hipóteses, uma ameaça à capacidade da comunidade política continuar se autogovernando.

A resistência, todavia, nem sempre é absoluta. O uso voluntário do direito internacional ou estrangeiro talvez possa ser considerado prática legítima na

${ }^{3}$ Conquanto muitas normas constitucionais sejam adotadas por emulação, aqueles que podem ser considerados particularistas afirmam haver uma diferença crucial entre escrever uma nova constituição - na qual seria possível e mesmo recomendável copiar normas de constitucionais bemsucedidas - e interpretá-la. Assim sendo, o direito estrangeiro e o direito internacional seriam irrelevantes para a interpretação de uma constituição de uma determinada nação, embora possam ser importantes no momento de sua elaboração.

${ }^{4}$ Atkins v. Virginia, 536 U.S 304, 348.

Revista Publicum

Rio de Janeiro, Número 2, 2016, p. 45-73.

http://www.e-publicacoes.uerj.br/index.php/publicum

DOI: 10.12957/publicum.2016.23767 
eventualidade dessas fontes confirmarem o entendimento original expresso pela soberania popular ao criar (ou reformar) a constituição que se esteja interpretando (JACKSON, 2010, p. 21-22). Há aqueles, por exemplo, que embora não se oponham completamente ao uso voluntário de fontes estrangeiras e internacionais sustentam que a invocação delas só deve ser considerada prática legítima quando realizada com o propósito de sustentar a constitucionalidade de uma lei, não o contrário (GLENDON, 2005). Fora desses limites, qualquer ato de interpretação baseado em fontes estrangeiras ou internacionais é considerado suspeito, podendo ser objeto de crítica.

Há inúmeros argumentos que alimentam uma postura de resistência. Embora não haja espaço para abordar todos os demais aqui, alguns merecem ser mencionados. Um muito comum envolve a questão a propósito da dificuldade contramajoritária. Afirma-se haver agora uma mais acentuada, uma "dificuldade contramajoritária internacional". (ALFORD, 2004, p. 57). Outra igualmente comum envolve desconfiança. Críticos afirmam que essa prática permite a invocação farsesca de fontes estrangeiras, possibilitando que juízes oportunistas "pincem" as decisões estrangeiras que lhes sejam mais convenientes, invocando apenas aquelas que apoiam uma posição particular, (MCCRUDDEN. 2000, p. 507) com o risco adicional de induzir outros juízes em erro.

Mas é preciso também afirmar que, muitas vezes, é difícil identificar manifestações doutrinárias de resistência, tendo em vista que ela, com muita frequência, toma forma de uma indiferença. Por exemplo, a falta de discussão a respeito pode ter como causa a falta de interesse ou disposição para o envolvimento voluntário com fontes jurídicas estrangeiras ou internacionais. Mas, sob análise, a aversão ao uso voluntário de fontes internacionais ou de alguns países, quando motivada pelo entendimento de que elas não são boas fontes, representa, na verdade, não uma resistência, mas uma forma de "envolvimento" com elas, já que a consideração delas como fontes de influência negativa já é em sim uma atividade comparativa. Ao mesmo tempo, pode-se afirmar que declarações de indiferença mostram-se autocontraditórias na medida em que elas manifestam a consciência da discussão. Ou seja, ao se declarar indiferente, o intérprete já se envolveu em uma comparação judicial.

Entendo que a questão a propósito da propriedade ou necessidade da comparação judicial está entrelaçada à discussão sobre os propósitos do próprio Direito Constitucional Comparado e a uma determinada ideologia sobre as quais trata a próxima seção. 


\section{Propósitos da comparação no Direito Constitucional e a}

\section{ideologia no direito comparado}

No direito constitucional comparado, reconhece-se que há considerável confusão quanto aos seus objetivos e propósitos específicos (HIRSCHL, 2014, p. 4). Não obstante isso, pelo menos três principais posições assumidas por acadêmicos com interesse nesse campo podem ser identificadas (ROSENFELD; SAJÓ, 2012, p. 9). Todas elas decorrem essencialmente de entendimentos diversos quanto à questão sobre se os problemas e soluções constitucionais são ou não universais. Ainda enfrentarei esse ponto mais detidamente à frente. Por ora, cabe afirmar que a primeira dessas posições sobre os propósitos do direito constitucional comparado assume que tanto os problemas como as soluções de Direito Constitucional são ou deveriam ser essencialmente os mesmos em todas as democracias constitucionais. Trata-se de uma posição universalista que acredita que o propósito do direito constitucional comparado é fornecer respostas universais a problemas constitucionais universalmente idênticos.

A segunda posição concorda com a afirmação de que os problemas são os mesmos, mas sustenta que as soluções não são ou podem não ser necessariamente idênticas. Essa é uma posição intermediária que sublinha as diferenças entre sistemas constitucionais que podem decorrer de vários fatores, como culturais e políticos. Com isso, embora os problemas possam ser idênticos, as respostas a eles variam de acordo com outros fatores que devem ser levados a sério. Com efeito, para essa segunda posição, o propósito do direito constitucional comparado é o de fornecer respostas apropriadas a contextos específicos, e não respostas universais.

A terceira e última posição não acredita que os problemas ou as soluções sejam os mesmos em todas as democracias constitucionais. Essa é uma postura cética que considera o direito constitucional comparado como arbitrário e ideológico, caso seu propósito seja o de fornecer as mesmas respostas para sociedades distintas. Para ela, os problemas podem ser, no máximo, próximos ou semelhantes. Mas as respostas a eles serão iguais ou devem ser sempre diferentes. Com efeito, pode-se deduzir que o propósito do direito constitucional comparado é unicamente o de conhecer os sistemas jurídicos. É essa terceira posição que os particularistas, conscientes ou não, parecem assumir. Mas ela, assim como a primeira, não é defensável, como ainda demonstrarei. Por ora, cabe mencionar uma questão subjacente a essas duas posições opostas.

A questão a propósito da ideologia do direito comparado é algo que segue controverso, mas é oportuno tecer algumas considerações. O que pode ser dito é que 
tanto aqueles que defendem a invocação judicial voluntária como aqueles que a rejeitam em favor do direito doméstico podem ter inclinações ideológicas. Quanto a esse ponto, pode-se afirmar que a diferença crucial não está entre os primeiros e estes últimos, mas entre aqueles que assumem que, no direito, não é possível que alguém se desfaça por completo de suas inclinações ideológicas e aqueles que rejeitam essa crença (ROSENFELD; SAJÓ, 2012, p. 42). Embora não haja razão para se pensar que apenas os comparatistas estão sujeitos às mais distintas ideologias, é necessário assumir que há uma em particular que mais separa aqueles que defendem a prática que estamos analisando de juristas que a rejeitam. Trata-se da ideologia nacionalista no direito. Juristas, políticos, acadêmicos e cidadãos de uma determinada comunidade política podem considerar importante manter suas identidades constitucionais e jurídicas em geral, considerando ideias jurídicas estrangeiras e internacionais como impróprias ou irrelevantes. Esse nacionalismo é mais acentuado no que diz respeito ao Direito Constitucional, já que essa área lida muito mais diretamente com a identidade nacional do que as demais. Contudo, também é preciso observar que, uma vez que toda comunidade política tem sua própria identidade constitucional (JACOBSOHN, 2010), seja ela semelhante ou bastante distinta de outras, a questão crucial não é sobre sua existência, mas sobre sua importância. E isso não é desconsiderado por aqueles que defendem a invocação voluntária de fontes não domésticas.

\section{A ideia de "Leis Parcialmente Comuns a toda Espécie}

\section{Humana" e seus desdobramentos}

Em um livro especialmente interessante, Jeremy Waldron (2012) recorre a uma ideia oriunda do direito domano do século II, mas presente nos Institutos de Gaio, para defender a necessidade de invocação judicial de experiências constitucionais estrangeiras: Omnes populi, qui legibus et moribus reguntur, partim suo proprio, partim communi omnium hominum iure utitur (Todos os povos governados por leis e costumes usam em parte suas próprias leis e leis parcialmente comuns a toda espécie humana para governarem a si mesmos). Essa ideia de "leis parcialmente comuns a toda espécie humana" era identificada como ius gentium. É com base nessa ideia que Waldron defende a invocação judicial voluntária do direito estrangeiro ${ }^{5}$. Mas não qualquer invocação. Não

${ }^{5}$ Waldron confere um sentido distinto a essa ideia. Mas o ius gentium, originalmente, era um elemento do sistema jurídico romano que surgiu em uma área específica da prática jurídica, o 
se trata de invocar um precedente ou uma lei de um ou mais países isoladamente. O que Waldron se dispôs a defender é a invocação de um consenso mundial de opiniões sobre determinada questão envolvendo direitos fundamentais. Como ele próprio afirma:

Eu acho que o consenso pode ter um status para nós que falta às citações avulsas, pelo menos quando elas são consideradas por conta própria. $O$ consenso é vinculante para nós como uma espécie de lei - lei para nós, pois é lei para o mundo inteiro - ao passo que ninguém considera que leis, precedentes ou doutrinas de apenas um país tenham alguma autoridade legal [sobre um determinado sistema doméstico]. (2012, p. 48)

É a esse consenso mundial que ele dá o nome de ius gentium moderno. Em suas palavras:

lus gentium não é um direito promulgado, mas ainda assim é direito. Como direito, tem sua origem nos sistemas domésticos ao redor do mundo. Mas o seu efeito jurídico transcende esses sistemas particulares. Esse direito apresenta-se como um corpo de princípios que sistemas particulares podem fazer valer quando eles estão buscando resolver questões difíceis de forma sábia, justa e em harmonia com a forma como esses problemas são resolvidos em outros lugares do mundo (2012, 51-52).

Evidentemente, essa é uma ideia complexa e desperdiçaríamos muito tempo expondo a elegante defesa dela feita por Waldron. O que nos interessa são os desdobramentos da ideia deste importante jurista: os dois argumentos normativos que ele oferece para a inovação judicial voluntária do direito estrangeiro em questões envolvendo direitos fundamentais. O primeiro deles tem natureza pragmática. Sustenta que, ao recorrermos a fontes externas ao nosso próprio sistema, podemos aprender com outras jurisdições nas quais tribunais já resolveram casos semelhantes. O segundo, por outro lado, tem um núcleo principiológico. Não se baseia no caráter utilitário dessas consultas, mas em um princípio inerente às nossas práticas de julgar. Trata-se da máxima

comércio com os estrangeiros no território romano ou entre esses estrangeiros. Referindo-se à passagem de Gaio utilizada por Waldron, John Kelly afirma que "Essa passagem, tomada isoladamente, poderia dar a entender que os romanos haviam se interessado cientificamente pelos sistemas jurídicos de outros povos e, pelo estudo comparativo, haviam chegado à conclusão de que certas normas eram as mesmas em todos os lugares. Isso não é verdade. Os romanos, como outros povos antigos, tinham pouquíssimo interesse pelas instituições de seus vizinhos" (KELLY, 2010, p. 80). 
segundo a qual se deve julgar casos iguais da mesma forma. Ambos os argumentos serão mais detidamente expostos e seus "excessos" examinados a seguir.

\subsection{Recorrer a um consenso jurídico entre nações?}

Cortes domésticas, ao consultarem as jurisprudências ou normas estrangeiras ou internacionais, podem, algumas vezes, aprender com uma determinada corte ou sistema jurídico ou mesmo com algumas cortes ou sistemas jurídicos diversos. Isso é inegável. E tendo em vista a possibilidade de aprendizado, muitos têm recomendado que tribunais nacionais, em especial Cortes Constitucionais ou Supremas, assim procedam ao analisarem casos controversos de direitos fundamentais. No entanto, é preciso um argumento mais forte para mostrar que essa prática não é apenas recomendável, mas devida. É aqui que entra a interessante analogia sugerida por Waldron entre o método jurídico e o método científico. Em poucas palavras, a ideia de que o que um juiz ou um tribunal em determinado país pode aprender com outras jurisdições é bastante parecido como o que um cientista em um laboratório pode aprender com os resultados científicos alcançados por outros cientistas até o momento.

Waldron parte da ideia de consenso científico ou estado atual do conhecimento científico compartilhado e acreditado pelos laboratórios e autoridades científicas em todo o mundo. De fato, como ele afirma:

há a comunidade de cientistas, e existe consenso dos cientistas para o momento em que teorias são válidas, que explicações são adequadas, quais resultados empíricos são confiáveis, quais construções teóricas são úteis, ondem residem os problemas intratáveis e qual o estado atual de tudo isso (p. 100).

Não há dúvidas de que esse consenso é precário e está continuamente em evolução, assim como pode ele não ser unânime ou infalível. Todavia, todos os cientistas no mundo pensam em termos deste consenso, senão como última palavra, ao menos como um ponto de partida. Seu valor para pesquisas atuais e futuras é inegável. Portanto, é impensável que alguém, ao se engajar em uma pesquisa sobre um determinado assunto, ignore um consenso atual a seu respeito. Mesmo se algum cientista não concorde com o atual consenso e tenha razões suficientes para não o considerar verdadeiro, ainda assim, ele não deve desconsiderá-lo. Em resumo, o consenso existente e reconhecido está 
disponível como uma fonte de conhecimento ou como um ponto de partida para o esforço científico de outros cientistas ao redor do mundo. Como diz Waldron:

Um cientista não pensa em prosseguir em uma investigação sobre a gravidade ou energia sem referência ao trabalho já realizado pela comunidade científica. Ele se baseia em e começa a partir de resultados estabelecidos e verificados. E o mesmo é verdade para o direito. Nós não tentamos resolver [nossos] problemas como se o mundo nunca tivesse lidado com eles. Damos atenção para o que outros juristas fizeram ao enfrentarem o problema. Tratamo-lo como um problema a ser resolvido dando atenção às opiniões estabelecidas pela ciência jurídica - a experiência que compartilham muitos sistemas jurídicos em combatê-lo, esclarecê-lo, analisá-lo, de resolver reivindicações rivais e direitos em colisão, princípios e valores que se juntam em questões desse tipo (p. 103)

Portanto, para Waldron, "[h]á uma analogia útil e esclarecedora entre o papel representado pelo consenso e a comunidade na ciência e aquele representado pelo consenso e comunidade jurídica global no direito". (p. 101) Essa analogia pode ser ilustrada da seguinte forma: tal como as autoridades nacionais de saúde ao enfrentarem uma doença nunca antes detectada em seu território não devem olhar apenas para os conhecimentos científicos desenvolvidos dentro de seu país ao decidirem qual deve ser o melhor tratamento a ser dado aos pacientes, também os juízes e tribunais de um determinado sistema não deveriam olhar apenas para suas leis e doutrinas nacionais ao decidirem os casos complexos que se repetem ao redor do mundo.

Mesmo que as autoridades de saúde sejam cientes de que as diferentes condições climáticas e outros fatores locais devam ser levados em consideração, ao pensarem em um tratamento, ainda assim seria insensato que eles desconsiderassem e ou resistissem a investigar se há alguma espécie de consenso científico a propósito do tratamento a ser dado aos pacientes nessa situação. Do mesmo modo, mesmo que juízes e juristas reconheçam que aspectos culturais ou políticos de seus sistemas devam ser levados em consideração ao analisarem os casos que devem julgar, ainda assim seria insensato que eles desconsiderassem ou resistissem a investigar se há alguma espécie de consenso jurídico sobre o caso em questão.

Como lembra Waldron: 
o mundo tem a experiência de responder a diferentes condições, e faríamos bem em aproveitar essa experiência para assegurar que não respondemos arbitrariamente ou irracionalmente às peculiaridades locais (2012, p. 102)

A analogia de Waldron tem a vantagem de tratar os problemas levados aos tribunais como problemas para ciência jurídica e não apenas para os juízes que os compõem. No entanto, a ideia de um ius gentium como analogia ao consenso global na ciência é problemática, mesmo que um “consenso de menos de cem por cento" (p. 187). É problemática não apenas por ser questionável a existência de consensos sobre questões jurídicas, mas também por que ela limitaria a própria prática que Waldron tenta justificar. Sobre muitas questões difíceis envolvendo direitos fundamentais que se repetem ao redor do mundo não há consenso, mas ainda assim os tribunais que as conhecem têm o dever de dar respostas a elas e seria bastante insensato aconselhá-los a não consultarem experiências estrangeiras tendo em vista não haver um consenso a respeito. Embora não haja espaço aqui para expô-los, o direito comparado possui inúmeros benefícios (SCHADBACH, 1998). De todo modo, é possível afirmar aqui que, na hipótese de não haver um consenso a propósito de uma questão, ainda assim a consulta judicial voluntária tem seu valor. Não são apenas supostos consensos que podem ser considerados como pontos de partida em uma empreitada científica. E a suposta existência de um consenso não é a única razão a justificar que uma interpretação comparativa não é só recomendável, mas necessária. Afinal, nada impede que um cientista dedicado a resolver um problema para o qual não há um consenso científico mundial tome, como ponto de partida, experimentos já realizados anteriormente por alguém. É claro que ele utilizará critérios racionais para escolher o ponto de partida. Daí a importância de critérios de comparabilidade, sobre os quais falaremos mais adiante.

É preciso reconhecer que, às vezes, a "comunidade" jurídica não tem uma resposta para um caso, mas um ou mais "integrantes" dessa comunidade podem já ter sugerido uma. Não seria sensato que as autoridades sanitárias de um país deixassem considerarem a(s) experiência(s) de outro(s) simplesmente pelo fato de não haver um consenso científico a propósito do tratamento a ser dispensado a uma doença inédita em seu país. Os tribunais e laboratórios, tal como os indivíduos responsáveis, podem não chegar a uma resposta correta ou à cura de uma doença, mas as buscam. Como os laboratórios, os tribunais, ao buscarem uma resposta a determinado caso, devem considerar todo o conhecimento disponível. Na ausência de uma certeza, isso é tudo que podemos exigir deles. Como veremos, é possível aprender com outras jurisdições na falta de consenso 
(qualquer que seja sua medida) a propósito de algum caso controverso. Antes, porém, analisemos o segundo argumento normativo sugerido por Waldron.

\subsection{Tratar casos iguais de forma igual ao redor do mundo?}

O segundo argumento normativo sugerido por Waldron "é a ideia de que a referência ao direito estrangeiro pode ser compreendida como um modo de assegurar coerência no mundo" (p. 111). Ele usa o termo "coerência no sentido de tratar casos iguais de forma igual" (p. 111). Sem dúvidas, muitos argumentos podem ser oferecidos para se reivindicar o respeito aessa máxima dentro de um determinado sistema jurídico. No entanto, argumentar a favor dela num plano transnacional é tarefa bem mais difícil, já que essa máxima equivale à exigência de harmonização interpretativa entre diferentes países, que é o que Waldron defende.

Segundo Waldron, o que justifica uma harmonização é a própria máxima segundo a qual devemos tratar casos iguais de forma igual, tendo em vista que ela própria é um requisito fundamental de justiça (fairness). Em sua defesa, ele novamente faz uso de uma analogia. Vejamos:

\footnotetext{
Imagine um grande campo de refugiados após uma escassez extrema de alimentos ou uma emergência humanitária, onde, como muitas vezes acontece, várias agências de ajuda e ONGs estão trabalhando lado a lado com a mesma grande população no mesmo campo. Suponha que uma dessas organizações torna-se ciente de que a prestação que está oferecendo aos refugiados é bastante diferente em quantidade e qualidade da prestação que as outras agências de ajuda estão oferecendo aos membros da mesma população no mesmo campo. A Oxfam, por exemplo, está dando duas refeições por dia para as pessoas na parte norte do acampamento, e outras agências estão dando uma refeição por dia para pessoas no setor sul, mesmo que as pessoas do norte não sejam mais necessitadas e não mais merecedoras do que aquelas do sul. E todos podem ver o que está acontecendo. Parece-me que a Oxfam e de fato todas as organizações reconheceriam que há um problema aqui - um problema que não evapora ou deixa de ser motivo de preocupação quando se diz que nenhuma instituição em particular está tratando alguém de forma inconsistente. As pessoas do sul são suscetiveis de serem afligidas pelo tratamento desigual. Elas são propensas a queixarem-se de que seu tratamento é injusto. Elas podem exigir que casos iguais sejam tratados da mesma forma. (p. 111)
}

Revista Publicum

Rio de Janeiro, Número 2, 2016, p. 45-73.

http://www.e-publicacoes.uerj.br/index.php/publicum

DOI: $10.12957 /$ publicum.2016.23767 
Essa metáfora, segundo Waldron, serve para explicar porque a exigência de coerência e harmonização pode ser feita mesmo estando envolvidas mais de uma instituição responsável pela aplicação da justiça em um mesmo local. Ele sugere que a analogia do campo de refugiados é aplicável ao mundo ou a boa parte dele. Como ele diz: "assumo que muitos países têm declarações de direitos bastante similares" (p. 133). Naturalmente, não há uma única autoridade administrando esses direitos. Ainda assim, diz ele, as pessoas nos diferentes países estão conscientes dos direitos individuais que são concedidos similarmente aos outros sujeitos às leis de outros países. Eles sabem que seu governo está lidando com os mesmos princípios, as mesmas questões e as mesmas circunstâncias. Então, eles se perguntam por que os governos não trabalham juntos para garantir que, neste mundo, os casos sejam tratados de forma igual. Como diz Waldron, "[s]ob essas circunstâncias, eu acredito que é possível começar a pensar sobre todos os povos como membros de uma única comunidade na medida em que a administração dos direitos humanos está em causa" (p. 133). Mas ele acrescenta:

Eu não quero ser fantasioso sobre qualquer cosmopolitismo mais amplo. Estou falando não sobre uma comunidade global para todos os fins, mas sobre algo como um clube do qual todos os povos são membros, um dedicado especificamente ao avanço da ideia de direitos humanos para todos, a pressionar os governos (de que todos temos muito a temer a este respeito, bem como muita esperança) para levar os direitos a sério e olhar para o outro quando direitos estão em jogo (p. 133).

Conclui, então, Waldron que esse tipo de argumento "pode ser feito em favor de uma justiça global e em favor da demanda por harmonização que é baseada nessa ideia" e que "essa ideia, talvez juntamente com o argumento sobre aprendizagem, fornecem a melhor explicação sobre o que está acontecendo quando os tribunais de um país prestam atenção ao que os tribunais de outros países estão fazendo a propósito dos direitos fundamentais" (p. 135).

Sem nenhuma dúvida, há muitos pontos passíveis de questionamento na argumentação de Waldron e para alguns deles ele tenta oferecer respostas com admirável humildade. Como esclarecemos, nosso propósito não é analisar por completo a tese de Waldron, mas tentar aproveitar suas duas principais ideias normativas para a justificação da invocação voluntária de experiências estrangeiras por tribunais nacionais na 
interpretação dos direitos fundamentais. As duas próximas seções buscam fazer exatamente isso.

\section{Um arcabouço para a análise de comparabilidade na interpretação judicial comparativa dos direitos fundamentais}

Há duas críticas quase universais à invocação voluntária (ou não) do direito estrangeiro por tribunais e juízes nacionais. A primeira delas diz respeito à ausência de metodologia ou, mais precisamente, de critérios a serem empregados. Muitas vezes essa crítica sugere que os tribunais e juízes escolhem os precedentes estrangeiros e internacionais mais adequados para apoiarem seus próprios pontos de vistas, sendo a invocação, portanto, apenas uma prática farsesca, um modo seletivo e estratégico de legitimar uma opinião já formada. A segunda crítica é a de que, mesmo nos casos em que os juízes e tribunais se esforçam em selecionar e invocam de boa-fé fontes estrangeiras em suas decisões, eles falham em identificar quais materiais comparativos são apropriados (BOBEK, 2013, p. 240). Isso se dá, em outras razões, devido ao fato de eles não compreenderem satisfatoriamente os contextos sociais e os sistemas jurídicos dos países dos quais os materiais comparativos são invocados, o que pode acarretar disfunções de alguma ordem no sistema doméstico. Em resumo, ainda que não seja farsesca ou arbitrária, a invocação voluntária pode ser arriscada quando não adotados os devidos cuidados.

Waldron reconhece esse risco e acusa a Suprema Corte norte-americana, dizendo que ela "move-se de um tipo de citação para outro sem qualquer estrutura teórica específica para explicar porque o envolvimento em um consenso global é sensato em um caso enquanto a citação de um único sistema jurídico estrangeiro ou um pequeno grupo deles é sensato em outro caso" (p. 76). Embora ele nos peça para interpretar o seu argumento em favor da invocação voluntária do direito estrangeiro como significando que "às vezes aprendemos com um sistema jurídico estrangeiro, às vezes aprendemos com alguns tomados em seu conjunto, e às vezes aprendemos com todos eles", a analogia que ele faz entre o "consenso científico" e um "consenso jurídico" exige que as cortes não "simplesmente olhem para 'modismos estrangeiros'”. Ao invés disso, a analogia insiste na "ideia de que soluções para determinados tipos de problemas jurídicos podem ser estabelecidas do mesmo modo que as teorias científicas são estabelecidas" (p. 103). Ou seja, a sugestão de Waldron é de que a invocação voluntária deve ter como critério um 
suposto consenso em uma comunidade jurídica global, mesmo que seja um "consenso de menos de $100 \% "$. Eis aqui, a meu ver, o excesso do seu argumento.

É evidente que a ausência de critérios é um problema para a prática da invocação voluntária do direito estrangeiro. O receio do uso seletivo é bastante fundado. Mas essa falta não significa que a prática é sempre nociva. Na ausência de critérios para ela, a recomendação de que os juízes se restrinjam a um suposto consenso, seja qual for o seu nível, é problemática por diversas razões. Primeiro, é difícil determinar quando estamos diante de um consenso a propósito de um determinado problema controverso envolvendo direitos fundamentais. Embora não haja espaço aqui para uma discussão com a profundidade necessária, é claro que a história, a cultura jurídica e demais variáveis responsáveis pela particularidade de uma nação influenciam e devem ser considerados. Exigir uma adesão a um suposto consenso jurídico encerra o risco de subordinação do Direito Constitucional nacional a projetos particulares de outros sistemas, ou de um conjunto deles. Cortes têm decidido questões sobre direitos fundamentais de formas variadas ao redor do mundo, levando em conta as particularidades de suas sociedades. Essas decisões podem estar assegurando direitos fundamentas e mantendo, ao mesmo tempo, a integridade dos seus sistemas e valores. Segundo, um suposto consenso pode ocultar uma espécie de dominação jurídico-cultural, o que encerra o risco da invocação baseada em um consenso gerar disfunções nos sistemas jurídicos que se deixam influenciar sem o devido cuidado. Por exemplo, um país de tradição religiosa forte pode perder sua identidade constitucional ao aderir a um consenso (possivelmente ocidentalizado) sobre o significado da liberdade religiosa. Terceiro, com tantas variações ao redor do mundo, é difícil pensarmos em uma comunidade jurídica global ou regional, mesmo no que diz respeito a alguns direitos. A cada dia crescem as reinvindicações culturalistas no mundo e hoje há uma verdadeira guerra cultural transnacional.

Não estou negando a possibilidade de haver um consenso e de haver benefícios decorrentes de uma adesão a ele, acaso exista ou possa ser identificado. O que estou dizendo é que uma adesão acrítica a ele pode gerar disfunções e que na ausência dele ainda assim a comparação tem seu valor. É que mesmo não se reconhecendo um consenso jurídico global a propósito de determinadas questões, ainda assim os tribunais podem se beneficiar da consulta voluntária de experiências estrangeiras, inclusive quando elas forem únicas. Em resumo, considero que é possível preservar o argumento pragmático segundo o qual a invocação judicial voluntária pode ajudar os juízes e tribunais que a realizam a aprender com outras jurisdições, mas apenas se esse aprendizado não for limitado a um suposto consenso jurídico global ou regional. Em outras palavras, acredito 
que um juiz ou tribunal pode muito bem aprender com apenas um país mesmo que nenhum outro já tenha oferecido alguma resposta ao caso em questão. Ou seja, é perfeitamente possível aprender com experiências únicas. Logicamente, nesse caso, não há como falar em consenso, mesmo se se aceite um consenso de "menos de cem por cento". Ainda assim, é possível que a invocação seja "sensata", para usar o adjetivo utilizado de Waldron.

No entanto, é preciso que isso seja feito com alguma metodologia, com alguns critérios. É aqui que entra a discussão a propósito da comparabilidade judicial, ou seja, de princípios de orientação para a atividade de comparar no direito. Embora já haja algum progresso, “[o] trabalho de identificar princípios de orientação sobre a relevância e o peso dos direitos estrangeiro e internacional na interpretação constitucional apenas começou" (JACKSON, 2010, p. 183). Ainda assim, é possível pensarmos em alguns critérios de comparabilidade visando a aumentar a autoridade persuasiva de fontes não domésticas. $O$ próprio Waldron sugere alguns critérios para identificar um grupo de países para encontrar o consenso por ele exigido entre "nações civilizadas" (2012, p. 190). Sugiro a seguir um arcabouço para a análise de comparabilidade na invocação judicial de fontes estrangeiras. Antes, porém, é preciso mencionar uma distinção muitas vezes desconsiderada.

Com frequência, juízes e tribunais recorrem a fontes não domésticas apenas com o propósito de demonstrar o quão similares ou diferentes são as constituições, as normas definidores de direitos fundamentais, os sistemas constitucionais como um todo e até mesmo a sociedade referenciada. Também com certa frequência, a invocação é feita com o propósito de tornar mais clara a compreensão de valores plasmados nos textos constitucionais domésticos. Ou seja, nem sempre se recorre a fontes estrangeiras como autoridades persuasivas para se tomar ou deixar de tomar determinada decisão. Às vezes, o uso é meramente "elucidativo", sem nenhum propósito além dos de ilustrar diferenças e semelhanças e de tentar melhor compreender valores constitucionais. Nesses casos, estáse diante de um modo de uso para o qual não se exige que os países ou sistemas possuam comparabilidade entre si. Afinal, uma fonte de um país diferente pode ajudar a esclarecer a natureza dos direitos fundamentais domésticos interpretados e a serem aplicados pela Corte. "Por essa razão", como diz Vicki Jackson:

$$
\begin{aligned}
& \text { a consideração de experiências mesmo de países que possam ser } \\
& \text { considerados como modelos negativos pode também ajudar no }
\end{aligned}
$$


esclarecimento ou na checagem do valor [plasmado em norma constitucional doméstica] (2010, p. 178).

Exige-se, porém, comparabilidade, no sentido de similaridade, quando fontes estrangeiras são invocadas como autoridades persuasivas positivas ou negativas. Uma fonte possui autoridade persuasiva positiva quando ela tem alguma força argumentativa que oriente um tribunal a tomar uma determinada decisão. Para os juízes e Cortes, uma "autoridade estrangeira é persuasiva porque ela os ensina algo que eles não sabem ou os ajudam a ver um problema em uma luz diferente ou mais tratável. Ela fornece um âmbito mais amplo de ideias e de experiência que tornam as decisões melhores e mais refletidas" (SLAUGHTER, 2003, p. 201). Por outro lado, uma fonte possui autoridade persuasiva negativa quando ela serve de argumento para que o tribunal ou juiz, pelo contrário, evite tomar uma dada decisão, seja pelo seu conteúdo, seja pelos seus efeitos. Em ambos os casos, porém, a fonte estrangeira invocada voluntariamente serve como auxílio argumentativo para o tribunal ou o juiz determinar qual decisão a ser tomada em determinado caso. Esse uso "funcional" de fontes estrangeiras impõe certos desafios e exige a adoção de alguns critérios sobre os quais trataremos brevemente a seguir. De qualquer modo, juízes e tribunais podem aprender tanto com o uso elucidativo quanto com o uso funcional de fontes estrangeiras.

\subsection{Selecionando o(s) paíse(s)}

A primeira observação que devemos considerar é a de que nem todas as nações serão capazes de fornecer materiais adequados para o uso comparativo em determinado país. Pondo de outro modo, para a comparação, "uma comunidade global de cortes não inclui todas as cortes de todos os países" (SLAUGHTER, 2003, p. 194). Portanto, deve haver alguma seleção, por meio da qual se deve separar nações adequadas daquelas não adequadas. Afinal, a autoridade persuasiva estrangeira irá variar claramente de país para país. De qualquer modo, se alguma seleção precisa ser feita, alguns critérios precisam ser adotados.

Talvez o critério mais consensual seja o regime político. É, de fato, muito importante considerar, sobretudo quando se busca uma autoridade persuasiva positiva, se o regime político do país de cuja fonte legal ou institucional estamos recorrendo é democrático. A democracia, inegavelmente, tem um valor de peso quando se trata de buscar exemplos a serem seguidos. "Isso sugere", como afirma Cass Sunstein, "que os juízes não deveriam pesquisar materiais de nações estrangeiras que possuem instituições 
altamente autoritárias ou disfuncionais" (SUNSTEIN, 2011, p. 107). Talvez, o regime mais apropriado a se considerar como produtor de fontes com autoridade persuasiva para países constitucionalizados seja o de democracia liberal. Esse critério é racional por que se presume que uma democracia ou, mais precisamente, as instituições políticas de estados liberais democráticos lidam com os direitos fundamentais de modo bastante diferente do modo como os regimes autoritários ou totalitários tratam esses direitos e seus titulares. Portanto, como ponto de partida, devem-se buscar fontes de países comprometidos com formas democráticas de governo, que respeitem direitos liberais e o Estado de Direito. Para esse propósito, é recomendável a busca por avaliações independentes, como as realizadas pela Freedom House ${ }^{6}$.

Observe-se que, considerando esse critério, as constituições dos países envolvidos na comparação sequer precisam ser parecidas. O Reino Unido, por exemplo, em muitos casos, pode ser uma boa fonte de comparação para os juízes norte-americanos, mesmo não tendo aquele país uma constituição escrita. Pode ele, inclusive, fornecer fontes constitucionais muito mais adequadas do que outros países cujas constituições escritas foram desenhadas com inspiração na Constituição norte-americana, mas que, não obstante, sejam ou ainda tenham resquícios autoritários, como é o caso da Argentina. Do mesmo modo, tomando ainda como exemplo os Estados Unidos, embora a Rússia seja, como eles, uma federação e tenha, como eles, uma constituição escrita, ainda assim não seria ela, pelo menos não a princípio, uma boa produtora de materiais comparativos, tendo em vista não ser um Estado livre.

O "pelo menos a princípio" anterior tem uma razão. Não basta selecionar países que adotem um regime genuinamente democrático e liberal. É preciso olhar para dentro dessas nações e analisar se suas instituições são genuinamente democráticas e liberais. Em alguns casos, as instituições ou a instituição a cuja fonte se invoca é tão democrática quanto à nação a qual pertencem. Por outro lado, em certos casos, uma nação que pode não ser considerada genuinamente liberal e democrática, como a Rússia no exemplo anterior, pode ainda assim possuir cortes independentes e com decisões que demonstram sua disposição em implementar direitos fundamentais, segundo as exigências de uma genuína democracia liberal. Portanto, embora não se possa negar que os estados nacionais ainda importam e que alguns estados nacionais importam mais do que outros, não é aconselhável nem considerar às cegas um país considerado democrático nem rejeitar todas as fontes de uma determinada nação apenas pelo fato de ela, de um modo

${ }^{6}$ Cf. https://freedomhouse.org/report-types/freedom-world\#.VUU3WM4VeOM 
geral, não poder ser considerada um Estado democrático e liberal genuíno, pois dessa rejeição pode decorrer uma exclusão indevida de materiais comparativos valiosos.

O oposto também é verdadeiro. É que, embora as credenciais democráticas das nações sejam importantes, é preciso ter cautela, já que em nações democráticas podem existir instituições não tão democráticas ou dispostas a protegerem direitos fundamentais contra os cursos de ação do Estado. Afinal, como tem sustentado a teoria liberal do direito internacional (SLAUGHTER, 1995), as instituições de uma nação comportam-se de modos bastante variados, inclusive de forma reacionária.

Não basta, portanto, o olhar macro sobre a nação. Importa igualmente olhar para dentro dela. É possível, inclusive, aprender com uma ideia elaborada por uma corte, mas que não tenha funcionado em seu país. Imagine-se a possibilidade de se tomar de empréstimo uma ideia pensada por uma determinada corte para um determinado caso em seu país, mas que não tenha sido bem-sucedida por alguma razão, como, por exemplo, devido a ausência de disposição por parte dos demais poderes para implementá-la ou por falta de condições econômicas para sua execução. É perfeitamente possível que essa ideia funcione bem no país que a toma de empréstimo quando as condições ausentes no país de origem estiverem presentes no país de destino.

\subsection{Verificando as características da(s) sociedade(s)}

Selecionado(s) o país(es) ${ }^{7}$ e checada a instituição da qual emana a fonte a ser invocada, um segundo critério precisa ser considerado. Muitas nações e suas respectivas instituições podem ser genuinamente democráticas e liberais, mas suas respectivas sociedades e a(s) cultura(s) que a conforma(m) podem não ser semelhantes às do país consultante. É preciso, portanto, cautela. É que:

[c]onsiderando a larga ordem de possibilidades tanto dentro da sociedade como dentro da cultura, um empréstimo indiscriminado da autoridade persuasiva estrangeira sem um olhar mais atento às características sociais e

${ }^{7}$ No que diz respeito à quantidade de países a serem consultados, podemos aqui tomar de empréstimo o teorema do júri, conforme recomenda Cass Suntein: "O Teorema do Júri ensina que o valor informacional de um voto declina rapidamente após certo número de votos ter sido registrado. Em outras palavras, pesquisar 10 países é muito mais importante do que pesquisar 5; mas pesquisar 190 adiciona muito pouco além de uma pesquisa de 185. Talvez, os juízes devessem pesquisar materiais jurídicos de outros 10 a 20 países (relevantes) e não tentar pesquisar os materiais jurídicos de todos os 190 ou mais países. Isso permitirá a eles gastar mais tempo evitando erros e reduzirá a informação agregada a muito pouco." (2011, p. 207). 
culturais que deram origem a tal autoridade pode, de fato, levar a resultados perigosos (GLENSY, 2005, p. 423).

Portanto, o valor da análise comparativa está condicionado também à existência de certas características comuns fundamentais entre as instituições das nações que estão sendo comparadas. Dependendo da área e do caso analisado, é mais provável que a invocação seja apropriada quando sistemas jurídicos comparados compartilham aspectos socioculturais, econômicos ou políticos (SCHADBACH, 1998, p. 362). Como afirma Aharon Barak (2002, p. 111):

O direito comparado não é apenas a comparação de leis. A comparação útil só pode existir se os sistemas jurídicos têm uma base ideológica comum. $O$ juiz deve ser sensível à singularidade de cada sistema jurídico. No entanto, quando o juiz está convencido de que as circunstâncias sociais, históricas e religiosas relativas criam uma base ideológica comum, é possivel referir-se a um sistema jurídico estrangeiro como fonte de comparação e inspiração.

A busca, porém, por fontes culturalmente compatíveis não pode dar lugar a um "chauvinismo cultural" (LANFBEIN, 1997), ou seja, à alegação de que as diferenças culturais impedem-nos de adotar e adaptar ou tomar de empréstimo experiências de outros sistemas jurídicos, como supõem os contextualistas. É bem verdade que uma "cultura nacional" pode existir em certos países, mas, geralmente, esses países não possuem uma inclinação democrática ou liberal. Com muito mais frequência, em democracias liberais, a cultura local tende a variar. Embora a cultura seja importante, o que mais importa na comparação são os aspectos da sociedade (GLENSY, 2005 p. 420). Uma sociedade pode ter inúmeras culturas. Por exemplo, nos Estados Unidos, encontramos a cultura negra e a cultura amish, mas, ainda assim, podemos encontrar traços sociais comuns. Portanto, justificar a confiança na autoridade persuasiva de determinada nação sob o fundamento de que há uma afinidade cultural nacional entre os países pode ser um grande equívoco ou mesmo uma atitude farsesca. O foco excessivo na cultura pode inclusive tornar a comparação muitas vezes subjetiva e arbitrária. Diante disso, é preferível que o foco seja direcionado às afinidades entre aspectos das sociedades envolvidas na comparação, das quais várias culturas podem fazer parte. Exemplificando, deve-se analisar se na sociedade em questão os cidadãos são livres para professarem suas crenças e para expressarem seus pensamentos, se nela há um forte, fraco ou moderado 
patriotismo, quais pontos de vista prevalecem em relação à questões polêmicas, como as relativas ao discurso de ódio, aborto, eutanásia, dentre outros.

Ademais, é necessário que, ao se verificar a existência de aspectos da sociedade da qual se pretende invocar alguma fonte, deve-se fazê-lo atentando para o fator tempo. É que as sociedades naturalmente variam ao longo de sua existência e valores são reinterpretados diante de desafios que trazem as evoluções de toda ordem e o progresso em vários campos. Por exemplo, ao se analisar a sociedade americana, deve-se, analisar a sociedade atual, obviamente tomando em conta suas conquistas históricas e seu passado.

\subsection{Atentando para os aspectos situacionais}

Além dos dois critérios já mencionados, há que se atentar também para a necessidade de consideração dos aspectos situacionais que justificaram a decisão judicial que estabeleceu o precedente invocado, dada diversidade de possíveis situações de aplicação das normas e precedentes estrangeiros que estão sendo invocados. O juízo, portanto, sobre a adequação das fontes estrangeiras invocadas envolve necessariamente a consideração das circunstâncias e aspectos situacionais dos casos concretos originais ou das circunstâncias que deram ensejo às normas jurídicas invocadas, pelo menos daqueles aspectos considerados importantes pelas cortes e legisladores que os estabeleceram. Ou seja, na utilização de fontes estrangeiras, deve-se considerar o contexto específico e os aspectos situacionais relevantes, nos quais elas foram originalmente criadas, bem como as situações contempladas pela argumentação do tribunal de origem e pelos legisladores, sob pena de se incorrer em grave omissão, cujas consequências não são totalmente previsíveis.

\section{Tratando casos comparáveis comparativamente}

Como vimos anteriormente, o segundo argumento normativo de Waldron em favor da invocação voluntária do direito estrangeiro - a ideia de que casos iguais devem ser tratados de forma igual - leva-o a defender uma harmonização global ou regional da interpretação dos direitos fundamentais. Portanto, o argumento em favor de uma justiça global e em favor de uma harmonização no que diz respeito a esses direitos é baseado nessa ideia. Os argumentos de Waldron são extraordinariamente notáveis, mas acredito que o ponto de vista por ele professado é problemático em âmbito transnacional, podendo ser desafiado pelas razões brevemente expostas a seguir.

Revista Publicum

Rio de Janeiro, Número 2, 2016, p. 45-73.

http://www.e-publicacoes.uerj.br/index.php/publicum

DOI: 10.12957/publicum.2016.23767 
Nenhuma sociedade é igual. A razão é simples: cada uma possui traços características que as tornam únicas e identificáveis. Esses traços decorrem de um amálgama cultural em seu mais amplo sentido. Se as sociedades não são idênticas, o direito de cada uma delas tampouco o é. O direito, afinal, também é cultura, compreensão essa que tem ganhado cada vez mais adeptos no direito comparado em geral e no direito constitucional comparado, em particular. Como afirmam dois influentes comparatistas, "muitos estudiosos têm enfatizado a necessidade de uma abordagem abrangente para o direito comparado, movendo-o, assim, para além da abordagem tradicional da doutrina jurídica do 'direito como regras'” (HOECKE; WARRIGNTON, 1998, p. 495).

Portanto, alguns comparatistas têm defendido que o direito comparado será sempre um empreendimento malsucedido enquanto o comparatista compreender o próprio direito apenas como um mecanismo destinado a cumprir determinadas funções (COTTERREL, 2006). Eles argumentam essencialmente que o direito e sua compreensão envolvem muito mais do que a mera intepretação de regras jurídicas e decisões judiciais. Em outras palavras, o direito não pode ser compreendido corretamente a não ser que ele seja visto em um amplo contexto histórico, socioeconômico, psicológico e ideológico. Para os mais pessimistas, a comparação seria impossível devido ao fato de as sociedades serem únicas e singulares. Com efeito, e dado que as sociedades possuem entre si diferenças irredutíveis e indeléveis, comparar os sistemas jurídicos seria como comparar diferentes "visões de mundo". Em certa medida, eles estão certos. O erro, a meu ver, está na dose de ceticismo.

A comparabilidade é a qualidade de coisas comparáveis. Algo comparável não é o mesmo que igual. Assim como o direito não é igual ao redor do mundo, os casos a serem julgados pelos mais distintos tribunais não podem ser considerados idênticos pelas mesmas razões e por outras também. Afinal, as pessoas não são iguais, os contextos não são iguais, os valores não são iguais ou não são compreendidos da mesma forma etc. Qualquer descrição situacional completa confirma essas afirmações. Todavia, por mais distintos que sejam muitos casos, na maioria das vezes eles não são excepcionais a ponto de serem considerados, por assim dizer, os únicos exemplares de uma espécie. Portanto, é claro que existem características situacionais relevantes e que muitas delas sejam semelhantes quando casos diferentes são comparados, sobretudo quando sujeitos à mesma jurisdição, pois, do contrário não haveria sentido na máxima de tratar casos iguais de forma igual. No entanto, quando comparamos casos ocorridos em sociedades diferentes, embora não desaparecem, as características situacionais se tornam mais pálidas. Isso tudo sugere que a recomendação para se tratar casos iguais de forma igual ao 
redor do mundo ou é muito difícil de ser seguida ou no, mínimo, é repleta de perigos, encerrando riscos diversos.

Mas nisso tudo não existe nada que estorve a comparação judicial. Com afirma Aharon Barak, "a importância do direito comparado consiste em expandir os horizontes do juiz" (2002, p. 111). Isso é verdade. Mas o seu benefício não é apenas para o juiz. E isso pode ser ilustrado: alguém ciente de que um caso semelhante ao seu foi decido em outro país igualmente democrático e liberal cuja ordem constitucional reconhece o mesmo direito fundamental em questão e cuja sociedade possui traços característicos semelhantes à sua tem razões suficientes para reivindicar a consideração por parte do órgão judicial competente para julgar seu caso. Quando os casos forem suficientemente semelhantes, o judiciário do seu país tem o dever moral de considerar essa fonte, sem que, obviamente, isto signifique que eles estejam obrigados a segui-la. Os tribunais e laboratórios, tal como os indivíduos responsáveis, podem não chegar à certeza ou à verdade, mas devem buscá-las. Como os laboratórios, os tribunais, ao buscarem uma resposta a determinado caso, devem considerar todas as hipóteses e conhecimentos disponíveis. Isso é decidir com responsabilidade. Na ausência de uma certeza, isso é tudo que podemos exigir deles, mas já é algo.

Portanto, pelas razões já expostas, na intepretação constitucional comparativa não é recomendável que se trate casos iguais de forma igual, pois as variantes, sobretudo sociais e situacionais, desautorizam essa recomendação. Melhor será se formos menos exigentes e recomendarmos que casos comparáveis sejam tratados comparativamente, no sentido de exigir que os juízes e tribunais, ao decidirem os casos submetidos às suas jurisdições, considerem, por dever moral, casos semelhantes já decididos por outras cortes em países semelhantes com sociedades semelhantes.

Tudo isso não equivale a uma rejeição da reivindicação por harmonização entre sistemas ao redor do mundo ou apenas em âmbito regional. Apenas a torna menos exigente, reconhecendo aos órgãos judiciais que invocam ou que, por dever moral, devem invocar fontes estrangeiras, o que chamo de "margem de apreciação comparativa", sobre a qual, infelizmente, não há espaço aqui para maiores desenvolvimentos.

\section{Conclusão}

Neste artigo, busquei oferecer justificativas para a comparação judicial em casos envolvendo direitos fundamentais. Meu propósito, como deixei claro, era repropor os 
argumentos normativos oferecidos por Jeremy Waldron em versões menos ambiciosas e mais promissoras. Como busquei demonstrar, o argumento segundo o qual os órgãos judiciais de um país podem aprender com experiências estrangeiras é irrefutável. No entanto, é preciso que haja algum critério para que a invocação dessas experiências não acabe sendo farsesca e enviesada. Waldron oferece um critério geral: a invocação deve ser de um consenso jurídico mundial ou entre um grupo de nações civilizadas. Como argumentei, embora seja possível haver algum consenso no que diz respeito à interpretação de direitos fundamentais, na ausência dele, ainda assim a comparação judicial tem ser valor e, em alguns casos, a consideração de experiências estrangeiras será um dever moral. Assim, os órgãos judiciais de um país podem muito bem se beneficiar de experiências únicas de outros países, o que significa dizer que não só se deve esperar aprender de um suposto consenso.

A recomendação para se tratar casos iguais de forma igual ao redor do mundo encontra muitas dificuldades. Considerando que, pelas diversas razões expostas, não há casos iguais, sobretudo quando ocorridos em sociedades e sistemas jurídicos distintos, a melhor recomendação é a de se tratar casos comparáveis de forma comparativa. Embora os casos ocorridos em países diferentes não sejam criteriosamente iguais, é possível, com base em critérios de comparabilidade, considerá-los como semelhantes. Afinal, a comparação é impossível entre objetos completamente distintos e desnecessária entre objetos idênticos.

Ofereci aqui apenas um arcabouço para a análise da comparabilidade na interpretação judicial comparativa dos direitos fundamentais. Sou ciente de que os critérios recomendados podem variar de acordo com as características sociais e constitucionais de cada país.

O que pode ser dito adicionalmente a título de conclusão é que o tema em geral é de grande fascínio e envolve inúmeras sutilezas, de modo que seria impossível tratá-lo aqui em profundidade desejável. Terei mais a dizer a respeito no futuro. Mas é já possível concluir que a comparação judicial, de um modo geral, é um desafio para os tribunais e juízes no direito constitucional contemporâneo.

\section{Referências Bibliográficas}

ALFORD, Roger $P$. Misusing international sources to interpret the constitution. The American Journal of International Law, vol. 58, 2004, p. 57-69. 
On limits on "grand theory" in comparative law. Washington Law Review, vol. 61,1986, p. $945-956$.

BARAK, Aharon. A judge on judging: the role of a Supreme Court in a democracy. Harvard Law Review, vol. 116, n. 1, 2002, p. 19-162.

BOBEK, Michal. Comparative reasoning in european Supreme Courts. Oxford: Oxford University Press, 2013.

CHOUDHRY, Sujit. Globalization in search of justification: toward a theory of comparative constitution interpretation. Indiana Law Journal, vol. 74, 1999, p. 819-892.

COTTERREL, Roger. Comparative law and legal culture. In: REIMANN, Mathias; ZIMMERMANN, Reinhard (eds.). The oxford handbook of comparative law. Oxford: Oxford University Press, 2006, p. 709-737.

DONNELLY, Jack. Cultural relativism and universal human rights. Human Rights Quarterly, vol. 6, 1984, p. 401-419.

FREIRE, Alonso. O Supremo Tribunal Federal e a migração de ideias constitucionais: considerações sobre a análise comparativa na interpretação dos direitos fundamentais. In: Clèmerson Merlin Clève; Alexandre Freire. (Org.). Direitos fundamentais e jurisdição constitucional. São Paulo: Revista dos Tribunais, 2014.

GLENDON, Mary Ann. Judicial tourism: what's wrong with the U.S. Supreme Court citing foreign.The Wall Street Journal. 16 de setembro de 2005. Disponível em: <http://www.wsj.com/articles/SB112683761327542620>.

GLENSY, Rex D. Which countries Ccount?:Lawrence v. Texas and the selection of foreign persuasive authority. Virginia Journal of International Law, vol. 45, 2005, p. 357-450.

GROPPI, Tania; PONTHOREAU, Marie-Claire (ed.). The use of foreign precedents by constitutional judges. Portland: Hart Publishing, 2013.

HIRSCHL, Ran. Comparative matters: the renaissance of comparative constitutional law. Oxford: Oxford University Press, 2014.

HOECKE, Mark Van; WARRIGNTON, Mark.Legal cultures, legal paradigmas and legal Doctrine: towards a new model of comparative law. InternationalandComparative Law Quarterly, vol. 47, 1998, p. 495-536.

JACOBSOHN, Gary Jeffrey. Constitutional identity. Cambridge, Mass.: Harvard University Press, 2010.

JACKSON, Vicki C. Constitutional engagement in a transnational era.New York: Oxford University Press, 2010.

KELLY, John. Uma breve história da teoria do direito ocidental. São Paulo: WMF Martins Fontes, 2010. 
LANGBEIN, John H. Cultural chauvinism in comparative law. Cardozo Journal of International \& Comparative Law, vol. 5, 1997, p. 41-49.

MCCRUDDEN, Christopher. A common law of human rights?: transnational tudicial Conversation on constitutional rights. Oxford Journalof Legal Studies, vol. 20, n. 4, 2000, p. 499-532.

ROBERTS, Anthea. Comparative international law?: the role of national courts in creating and enforcing international law. InternationalandComparative Law Quartely, vol. 60, n. 1, 2011, p. 57-92.

ROSENFELD, Michel; SAJÓ, András. Introduction In: ROSENFELD, Michel; SAJÓ, András (eds.). The oxford handbook of constitutional law. Oxford: Oxford University Press, 2012, p. 1-24.

SCHADBACH, Kai. The benefits of comparative law: a continetaleuropean view. Boston University International Law Journal, vol 16,1998, p. 331-422.

SIEMS, Mathias. Comparative law.Cambridge: Cambridge University Press, 2014.

SLAUGHTER, Anne-Marie.A global community of courts. Harvard Journal of International Law, vol. 44, n. 1, 2003, p. 191-220.

SLAUGHTER, Anne-Marie.International law in a world of liberal states.European Journal of International Law, vol. 6, 1995, p. 503-538.

SUNSTEIN, Cass R. A constitution of many mind: why the founding document doesn't mean what it meant before. Princenton: PrincentonUniversity Press, 2011.

TUSHNET, Mark. The possibilities of comparative constitutional law. The Yale Law Journal, vol. 108, n. 6, 1999, p. 1225-1310.

WALDRON, Jeremy. "Partly laws common to all mankind": foreign law in american courts. New Haven: Yale University Press, 2012. 